East African Medical Journal Vol. 87 No. 1 January 2010

INTERNAL ROOT MORPHOLOGY OF THE MAXILLARY FIRST PREMOLARS IN KENYANS OF AFRICAN DESCENT

R. N. Ng'ang'a, BDS, MDS, Senior Principal Lecturer, Department of Community Oral Health, Kenya Medical Training College, P.O. Box 30195 - 00100, Nairobi, Kenya, M.A. Masiga, BDS, MSc, Senior Lecturer, Department of Paediatric Dentistry and Orthodontics, S. W. Maina, BDS, MSc, Senior Lecturer, Department of Conservative and Prosthetic Dentistry, Faculty of Dental Sciences, University of Nairobi, P.O. Box 19676-00202, Nairobi, Kenya

Request for reprints to: Dr. R. N. Ng'ang'a, Department of Community Oral Health, Kenya Medical Training College, P.O. Box 30195 - 00100, Nairobi, Kenya

\title{
INTERNAL ROOT MORPHOLOGY OF THE MAXILLARY FIRST PREMOLARS IN KENYANS OF AFRICAN DESCENT
}

\author{
R. N. NG'ANG'A, M.A. MASIGA and S. W. MAINA
}

\begin{abstract}
Objective: To determine the internal root morphology of the maxillary first premolar in Kenyans of African descent.

Design: In vitro descriptive cross-sectional study.

Setting: School of Dental Sciences, University of Nairobi.

Subjects: One hundred and fifty five extracted maxillary first premolars obtained from patients aged between 13-30 years attending dental clinics within Nairobi.

Results: There were 77 premolars from males and 78 from females. Majority $(87.1 \%)$ of the teeth had two canals. Males presented with three canals more commonly than females. This difference was statistically significant. According to Vertucci's classification, male specimens demonstrated five of the canals types while female specimens demonstrated all the eight canal types. These differences were not statistically significant.

Conclusions: Kenyan maxillary first premolar was mostly found to have two canals. There were eight canal types, with type IV being the commonest.
\end{abstract}

\section{INTRODUCTION}

Endodontics is a sub-specialty of conservative dentistry dealing primarily with debridement of infected root canals and their subsequent obturation. In order to perform these procedures skillfully and effectively, dentists ought to understand tooth anatomy well, especially the internal morphology and the potential for variation in the root canal system (1). Before embarking on endodontic therapy, preoperative radiographs are necessary to show the external and internal morphological features of a $\operatorname{root}(2,3)$.

In many populations, the occurrence of two canals in the maxillary first premolar has been reported to range between $68.8 \%$ and $92.0 \%$ (4-9) irrespective of whether it has one or two roots. In less than $10 \%$ of cases the tooth may be three-rooted with three distinct canals, two buccally and one palatally $(5,10)$.

Vertucci and Gegauff (8) indicate that an examination of the floor of the pulp chamber may offer clues as to the number of canals present. When only one canal exists, it is easily probed in the centre of the access preparation. If only one orifice is found away from the centre of the preparation, another canal may probably be present, located on theopposite side. The two authors elaborated further on the relationship of two orifices to each other indicating that if they were more than $3 \mathrm{~mm}$ apart, the two canals remained separate throughout their length and if less than 3 $\mathrm{mm}$, the canals usually joined. The closer the orifices were to each other, the more coronal the union. They also observed that the tooth had five different canal types, making it a difficult tooth to root-fill. In a Turkish population, Caliskan et al (11) also observed five different canal types in this tooth. In both studies $(8,11)$, canal type $1 \mathrm{~V}$ was the most common.

Genetic determination of dental morphology and the anthropological associations of certain dental characteristics with certain racial groups have been reported (12-14). Currently, there is no information in the literature on the internal morphology of this tooth in Kenyans of African descent.

The aim of this study was to determine the internal morphology of the maxillary first premolar in Kenyan males and females of African descent with regard to the number and types of canals. 


\section{MATERIALS AND METHODS}

This was an in vitro study where freshly extracted maxillary first premolar teeth were collected from Kenyan patients of African descent aged between 13-30 years. The patients were attending the main government dental hospitals in Nairobi, Kenya (Kenyatta National Hospital, Social Service League Dental Clinic and University of Nairobi Dental Hospital).

Nairobi is a cosmopolitan city with a population of about 2.1 million people. The city residents are migrants from all parts of the country. The obtained specimens, therefore, represented different Kenyan ethnic groups.

Approval for the study was obtained from the Kenyatta National Hospital-Ethical Research Committee (KNH-ERC). In addition, permission to collect specimens was given by the various heads of the dental hospitals visited. All patients whose specimens were studied gave informed consent. The following categories of specimens were excluded from the study:

(i) Teeth from non-Kenyans and Kenyans of nonAfrican descent.

(ii) Teeth with developmental abnormalities of the crowns and roots.

(iii) Teeth with incompletely formed roots.

(iv) Teeth with fractured roots or those with extensive cementum deposition around the root apex.

(v) Contra-lateral (antimere) premolar tooth.

Most of the specimens were obtained from orthodontic patients.

In each hospital a dentist assisted in the collection of the teeth. The dentists were trained on the inclusion and exclusion criteria, and the importance of storing the specimens into the correctly labelled container.

Immediately after extraction, the premolars were stored for 30 minutes in $5.25 \%$ sodium hypochlorite solution in two plastic containers labelled according to gender. The specimens were carefully scrutinized with the help of a magnifying glass (x21/2 magnification) to confirm their suitability for study.

To study the internal morphology, the widely used decalcifying and clearing techniques were employed (15-18). The techniques involved several stages: An access cavity was made on each tooth using a high-speed hand piece and a diamond bur under a water spray. The canals were irrigated with 5.25\% sodium hypochlorite solution using a 22-gauge syringe for a minimum period of 30 minutes and then dried with paper points. India ink was injected into the canals using a 22-gauge syringe. To ensure adequate staining of the specimens, they were then immersed in India ink for a minimum period of four days. Subsequently, the decalcification process was started.

Complete decalcification was achieved after soaking the teeth in $5 \%$ nitric acid for four days. The nitric acid was agitated by hand three times each day and discarded daily. Following decalcification, the specimens were rinsed in running tap water for a minimum period of 4 hours. This was followed by dehydration in successive solutions of ethyl alcohol at concentrations of $70 \%, 95 \%$, and $100 \%$. A minimum of 5 hours was allowed at each concentration. Dehydration was carried out to facilitate clearing.

Clearing was done using methyl salicylate (oil of wintergreen) which is not miscible with water. This process was completed within 6 hours of immersing the teeth in methyl salicylate. The clearing agent modified the refractive index and eliminated reflection resulting in transparent specimens that revealed the stained pulp canals clearly.

Finally, the ink-dyed root canals were examined under a microscope at magnifications of $x 10$ for the less complex and x 40 for the more complex canal pattern.

One hundred and fifty five specimens (77 males-, 78 females) were successfully processed. The canal patterns were recorded according to Vertucci's (19) classification (Figure 1). After assigning each canal pattern to its classification, the specimens were photographed from the view that demonstrated the canal pattern most clearly. The photographs were taken using an SLR single lens reflex - 35mm Olympus camera (OM- 1) that was fitted with a $50 \mathrm{~mm}$ macro lens onto which a $x 2$ teleconverter was attached. The magnification in the camera was 1:1. The enlarger magnification was 3.5. The specimens were photographed under transmitted light to show stain intensity in the specimen and instance light to show specimen structure.

Oneauthor(R.N.N.) whowaspreviouslycalibrated in all aspects of the study carried out the processing of all the specimens, subsequent observations, classification and recording of the canal types. 
Figure 1

Diagrammatic representation of root canal types according to Vertucci's (19) classification

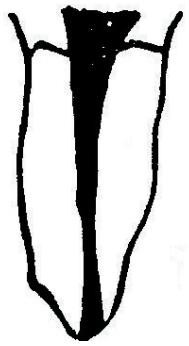

Type I: A single canal extends from the pulp chamber to the apex

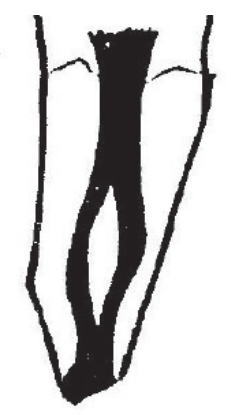

Type III: One canal leaves the pulp chamber, divides into two within the roots, and then merge to exit as one canal

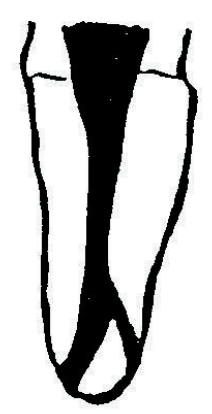

Type V: Only one canal leaves the pulp chamber and divides short of the apex into two separate and distinct canals with apical foramina

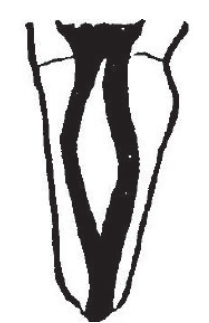

Type ll: Two separate canals leave the pulp chamber and join short of the apex to form one canal

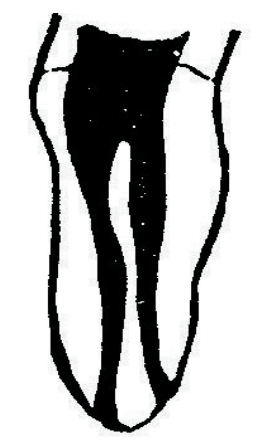

Type IV: Two separate and distinct canals extend from the pulp chamber to the apex

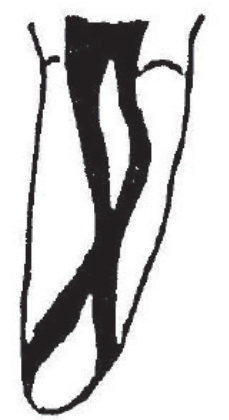

Type VI: Two separate canals leave the pulp chamber, merge in the body of the root, and re-divide short of the apex to exit as two distinct canals
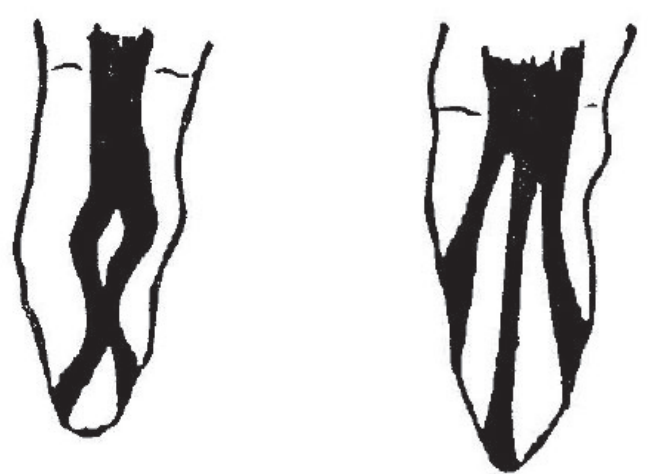

Type VII: One canal leaves the pulp chamber, divides and then rejoins within the body of the root, and finally re-divides into two distinct canals short of the apex

Data analysis: Data were analysed using SPSS (Statistical Package for Social Sciences) programme. Descriptive statistics were done to determine frequencies in number and types of canals. Pearson Chi-square test was used to assess gender differences in number of canals and canal types. In situations where assumptions of Pearson Chi-square tests were not met, Fisher's exact test was employed to assess gender differences in number of canals and canal types. The level of significance was set at 0.05 .

\section{RESULTS}

One hundred and fifty five (77 males, 78 females) maxillary first premolars were examined. In both gender most of the specimens $(87.1 \%)$ presented with two canals. Males had a higher percentage $(11.7 \%)$ of three canals than females (1.3\%) (Table 1).

Table 1

Distribution (\%) of number of canals by gender in maxillary first premolars

Gender No. of teeth Percentage no. of canals One Two Three*

\begin{tabular}{lllll}
\hline Male & 77 & 5.2 & 83.1 & 11.7 \\
Female & 78 & 7.7 & 91.0 & 1.3 \\
\hline Total & 155 & 6.5 & 87.1 & 6.5 \\
\hline
\end{tabular}

$\mathrm{x}^{2}=20.14 ; \mathrm{df} 2$;

$\mathrm{P}=0.002^{*}[\mathrm{p}<0.05]$

*significant difference (Fisher's exact test) 
The first maxillary premolar demonstrated eight canal types (Figure 2). Females presented with all the eight canal types while males presented with only five types. In both gender, canal type IV was the commonest, followed by type V (Table 2). Gender differences could only therefore be evaluated in canal types IV and V because they had adequate representation to permit statistical testing. No statistically significant gender differences $(P>0.05$, Pearson Chi-square test).

Table 2

Percentage number of root canal types by gender

\begin{tabular}{llllllllll}
\hline \multicolumn{1}{l}{ Gender } & No. of teeth & \multicolumn{9}{c}{ Canal types (I-VIII) } \\
& & I & II & III & IV & V & VI & VII & VIII \\
\hline Male & 77 & 2.6 & 2.6 & 0 & 68.8 & 14.3 & 0 & 0 & 11.7 \\
Female & 78 & 1.3 & 2.6 & 3.8 & 74.4 & 11.5 & 1.3 & 3.8 & 1.3 \\
\hline Total & 155 & 1.9 & 2.6 & 1.9 & 71.6 & 12.6 & 0.7 & 1.9 & 6.5 \\
\hline
\end{tabular}

\section{Figure 2}

Photographs of specimens from the present study after decalcification and clearing showing root canal type IVII according to Vertucci's (19) classification

I

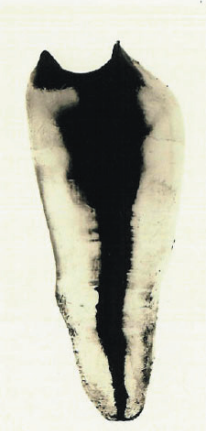

III

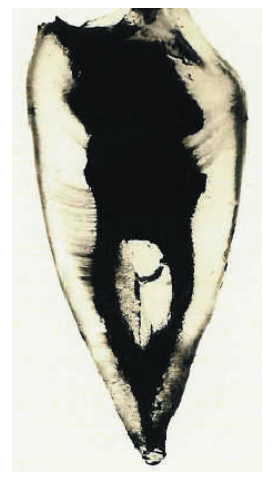

V

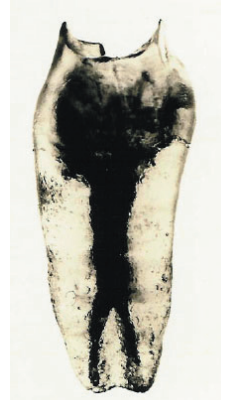

II

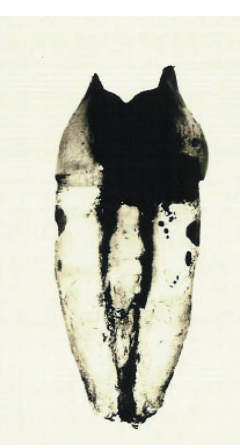

IV

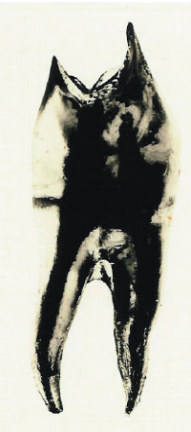

VI

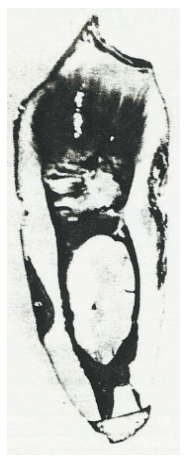

VII

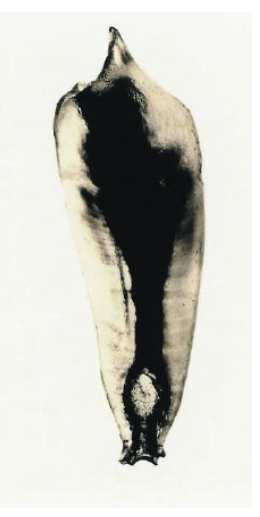

VIII

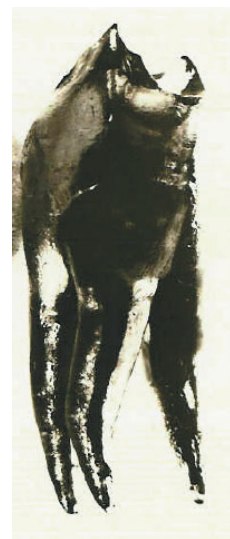

\section{DISCUSSION}

The objective of the present study was to determine the internal morphology of maxillary first premolars in Kenyans of African descent. This was done using the decalcifying and clearing techniques on the specimens (15-18).

Decalcification and clearing preserves the internal morphology and gives a three dimensional view of the pulp in relation to the exterior of the tooth (18). This method has been shown to be simple and efficient in the three-dimensional analysis of root canal patterns. The method used to classify canal patterns was that by Vertucci (19), allowing comparison of his findings with those of the present study.

The combined gender data for maxillary first premolars with one canal, two canals and three canals was comparable to that reported in the literature. Two canals were the most common $(87.7 \%)$. This was within the range of $73.3 \%$ to $98.5 \%$ reported in previous studies $(4,5,7,8,20)$. The occurrence of three canals in this tooth was $6.5 \%$, which is also within the 
reported range in the literature $(0 \%-7.5 \%)(4,7,8,20)$. When each gender was considered separately, three canals were more common in males than females. This difference was statistically significant $(\mathrm{P}<0.05)$.

Vertucci(19) reported five canal types in the maxillary first premolar tooth with canal type IV being the commonest. In that study, gender differences were not stated. In the present study, it was possible to demonstrate all of Vertucci's (19) eight canal types in female specimens but only five canal types in the male specimens (Table2). Although in both males and females type IV was the most common, there was no significant gender difference in this occurrence.

The fact that different canal patterns can occur within the same premolar tooth type emphasizes the importance of correct radiographic interpretation before embarking on endodontic therapy. It has been observed that premolars with canal bifurcations in the middle or apical third (type V, VI and VII) might present problems during endodontic treatment (19). It is likely that some of the canals are not always identified and obturated. This may explain some of the endodontic failures associated with these teeth, even though radiographically and clinically the canal system seems to be obturated (21). It has therefore been suggested that in addition to taking pretreatment radiographs from a bucco-lingual direction, a second radiograph at $20^{\circ}$ angle to the mesial or distal side should be taken because it may give a better view of the bucco-lingual anatomy (3). A radioluscent line next to the main canal may be observed in the second radiograph, which means that there may be another canal in that particular tooth.

The complicated canal patterns found in this study also indicate that complete debridement of the whole canal by mechanical means may be difficult to achieve. This emphasizes the importance of chemomechanical debridement of canals. When either pain or periapical breakdown is seen after apparently effective nonsurgical endodontic therapy, the possibility of an additional canal should be considered before the tooth is condemned or surgical endodontics is scheduled (11). When interpreting the above results, one has to bear in mind that the specimens were from "young teeth" (patients between 13-30 years). Teeth are known to undergo age- changes resulting in calcification of the pulp chamber and canals.

In conclusion, maxillary first premolars mostly presented with two canals and a complicated internal canal pattern. The commonest pattern noted was the Vertuci type IV. Three canals were seen to be more frequent in the maxillary first premolars of male participants.

\section{REFERENCES}

1. Ingle, J.I. and Glick, D.H. Endodontics. 2nd ed. Philadelphia: Lea and Febiger. 1976; 77.

2. Fishel, D. and Tamse, A. Dentists' mistakes in making correct radiographic diagnosis. Quit. Int. 1978; 6: 59-64.

3. Slowey, R. R. Radiographic aids in the detection of extra root canals. Oral. Surg. 1974; 37: 762-772.

4. Hess, W. Anatomy of the root canals of the teeth of the permanent dentition. Part 1.New York: William Wood \& Co. 1925.

5. Mueller, A.H. Anatomy of the root canals. J. Am. Dent. Assoc. 1933; 20: 1361-1386.

6. Green, D. Morphology of the pulp cavity of the permanent teeth. Oral. Surg. Oral. Med. Oral. Path. 1955; 8: 743-759.

7. Carns, E.J. and Skidmore, A.E. Configurations and deviations of root canals of maxillary first premolars. Oral. Surg. 1973; 36:880-886.

8. Vertucci, F.J. and Gegauff, A. Root canal morphology of the maxillary first premolars. J. Am. Dent. Assoc. 1979; 99:194-198.

9. Barrett, M.T. The internal anatomy of the teeth with special reference to the pulp with it's branches. Dent. Cosmos. 1924; 67:581-592.

10. Ingle, J.I., Beveridge, E.E., Luebke, R.G. and Brooks, E.V. Endodontics. Coronal endodontic cavity preparations. 2nd ed. Philadelphia: Lea and Febiger 1976; 106-213.

11. Caliskan, M.K., Pehlivan, Y., Sepetcioglu, F., et al. Root canal morphology of human permanent teeth in a Turkish Population. J. Endod. 1995; 21: 200-204.

12. Dahlberg, A.A. Geographic distribution and origin of dentitions. Int. Dent. J. 1965; 15: 348-355.

13. Bailit, H.L. Dental variation among populations: An anthropologic view. Dent. Clin. North Am. 1975; 19: 125-139.

14. Loh, H.S. Root morphology of maxillary first premolar in Singaporeans. Aust. Dent. J. 1998; 43: 399-402.

15. Rosenstiel, E. Transparent model teeth with pulps. Dent. Digest. 1957; 63: 154-157.

16. Tagger, M. Clearing of teeth for study and demonstration of pulp. J. Dent. 1976; 40:172-174.

17. Robertson, D., Leeb, J., McKee, M. and Brewer, E. A clearing technique for the study of root canal system. J. Endod. 1980; 6: 421-424.

18. Hasselgren, G., Nellestam, P. and Bynum-Hasselgren, R.M. Teeth with transparent roots. An improved teaching aid for preclinical endodontics. J. Endod. 1987; 13: 126-127.

19. Vertucci, F. J. Root canal anatomy of the human permanent teeth. Oral. Surg. 1984; 58:589-599.

20. Bellizzi, R. and Hartwell, G. Radiographic evaluation of root canal anatomy of in vivo endodontically treated maxillary premolars. J. Endod. 1985; 11: 37-39.

21. Stewart, G.G. Evaluation of endodontic results. Dent. Clin. North. Am. 1967; 11: 711-722. 